Original research paper

\title{
CONFORMITY TO MASCULINE NORMS AND ITS EFFECTS ON MEN'S WELL-BEING
}

\begin{abstract}
Given the body of evidence for the complex links between gender norms and well-being, examining the effects of masculine norms on men's health is increasingly becoming a focus of public health interest. This research is an attempt to shed light on the links between accepting different aspects of the hegemonic masculinity norms with self-esteem and life satisfaction on the one hand and depression, anxiety, stress, emotional closure and taking health risks on the other. The sample of participants included in the research consists of 310 men, ethnic Macedonians from 20 different cities in the country, aged between 20 and 30 years.

The results of the correlational analysis between the eight included variables, in addition to clearly confirming the need for analysis of various aspects of masculinity on men's behaviour, as opposed to using the general score only, suggest that for this age group, identification with hegemonic masculinity carries more potential risks than benefits. Thus, while the acceptance of the hegemonic ideal is positively related to self-esteem and life satisfaction in only a small number of aspects, most are associated with a reluctance to share emotions, depression, stress, anonymity, and health-threatening behaviours.
\end{abstract}

Keywords: MASCULINE NORMS, RISK BEHAVIOURS, WELL-BEING

\section{INTRODUCTION}

The socially construed and enforced rules, related expected traits and behaviours associated with men and manhood in a given culture are known as masculine norms. Connell (1995) proposed a model of hierarchy of masculinities where the hegemonic masculinity represents the culturally dominant ideal of what it means to be a man. In Western culture, hegemonic masculinity is linked with traits of competitiveness, self-reliance, emotional detachment, affluence, dominance, and physical strength. Although only relatively small proportion of men can adhere completely to the hegemonic masculinity, those who carry out practices indicating these traits, maintain a position of dominance as they are accepted as the ideal among the majority of men (Connell \& Messerschmidt, 2005). 
Two decades ago, Kivel (1998) coined the term "Man Box" to refer to the set of norms, or implicit rules and expectations, for socially accepted behaviour of men. One cannot state that all men have internalized these norms, however, as various studies (eg. Heilman \& Wallen, 2010; Ruble Martin, \& Berenbaum, 2006; Skinner et al., 2018) have revealed, most adolescent boys and men affirm that they have been encouraged or even seriously pressured to act in line with these expectations. It is well documented that when boys and men conform to the male norms, they are evaluated more highly than girls and women. Given the fact that characteristic attributed to masculinity, especially when it is hegemonic are valued higher than femininity and that it is one of the pillars over which men maintain dominant social positions over women and other gender identities perceived as non-masculine, it is expected that life satisfaction should be higher in men who conform more to the traditional role. In line with that, a recent study carried out across 48 nations once again confirmed the finding from almost all similar empirical studies that have been undertaken in western countries in the last two decades - males consistently report higher self-esteem than females (Bleidorn at al., 2016). Although empirical evidence regarding this association is only partial (DiDonato \& Berenbaum, 2013, Iwamoto, Liao \& Liu, 2010), it is very likely that for men in particular, gender typicality as opposed to non-typicality, contributes towards higher self-esteem and life satisfaction (Corby, Hodges, \& Perry, 2007).

Parallel to the many well documented benefits for the psychological well-being related to conforming to the male norm (eg. Kiselica, BentonWright, \& Englar-Carlson, 2016), gender sensitive health researchers are frequently warning about the dangerous effects of endorsement of traditional masculinity ideology (Ragonese, Shand, \& Barker, 2019). The most commonly mentioned negative effects associated with masculine gender role are the pressure for taking risks and involvement in violence, the restrictions of emotions, as well as high levels of stress, and anxiety related to the expectations to achieve and maintain social status.

Through the process of gender-role socialization, men are trained to perceive expressing and sharing certain emotions or seeking for emotional support as non-manly, because such behaviours supposedly indicate weakness or helplessness. Empirical findings clearly indicate that adherence to the masculine norm of emotional control is largely associated with interpersonal and emotional disconnection (Burns \& Mahalik, 2006, Ragonese, Shand, \& Barker, 2019). There are also indicators that practicing emotional control might lessen reporting depressive symptoms (Iwamoto et al, 2013), but it also contributes to inclination towards alcohol consumption as a mechanism for coping with negative emotions, anxiety and stress. In other words, alcohol abuse could be seen as a kind of "selfmedication" connected to the masculine norm that men should be emotionally self-sufficient and independent (Iwamoto et al, 2014; Uyet al, 2014).

The links among masculinity and alcohol consumption are much more complex and certainly go beyond the expectation for emotional control only. 
Alcohol use is also linked with the expectations for domination, courage, adventurousness and playfulness (Hussman, 2015; Silva et al, 2019), as well as with a sexual conquest script (Iwamoto, 2014). This script on the other hand, reinforces aversive attitude towards using condoms and taking higher risks of involving in unprotected sexual activities. Studies suggest that aversion to condoms largely stems from a masculine ideal of sexual performance which potentially could be disrupted. Consequently, engaging in unprotected sex has been in many ways identified as a correlate of hegemonic masculinity ideology (Noar \& Morokoff, 2002; Reidy et al, 2016).

Body of research has revealed a relationship between hegemonic masculine norms and other health related risk behaviours like smoking ( $\mathrm{Ng}$ et al, 2007). In some cultures, smoking is linked to masculinity via religious ceremonies, and much broadly, this link has been established due to the strategic marketing techniques that celebrate tobacco smoking as a symbol of roughness, freedom and independence. ${ }^{1}$ Although the masculine connotations of tobacco use are especially pronounced in less developed countries and among social strata with lower incomes, men still strongly associate smoking with physical resilience and strength, rationality and financial success (Bottorff, et al, 2014; Morrow, \& Barraclough, 2010).

This study is an attempt to address these contradictory effects of conforming to the masculinity norms - higher self-esteem and life satisfaction on one hand, versus higher stress and depression along with acceptance of health risks on the other. The focus is on the developmental phase of early adulthood (between 20 and 30 years of age) when young adults become more independent, explore different life possibilities and search for sexual intimacy. Based on earlier findings, it was hypothesized that conforming to masculinity norms has positive effects on self-esteem and subjective well-being, while it contributes to higher stress, depression and anxiety, less emotional disclosure and proneness to risk related behaviours, such as avoiding condom use and higher tobacco and alcohol consumption.

\section{METHOD}

\section{Participants}

The sample comprised 310 male participants, all ethnic Macedonians, who live in 20 different towns/cities in the country (35\% from Skopje). Their age range was from 20 to $30^{2}(M=24.5, S D=2.85)$. The vast majority of participants declared themselves as heterosexual (93\%), whereas $1.5 \%$ stated that they identify themselves as homosexuals, $1.5 \%$ as bisexual and the rest did not res-

\footnotetext{
${ }^{1}$ Although banned, the advertisements of iconic brands Marlboro Man or Camel (with its slogan Where a Man Belongs) are examples of such messages.

${ }^{2} \mathrm{CMNI}-46$ was normed on a group of predominantly single heterosexual college-attending males averaging 20 years old who live in USA.
} 
pond. Almost half (44.2\%) are in a relationship, $43.9 \%$ are single, $9.4 \%$ are married and $2.6 \%$ did not report their status. More than half of them $(55.5 \%)$ are employed and $45.4 \%$ have completed higher education.

\section{Instruments}

The included instruments were translated from English into Macedonian and back translated into the original language by an independent professional translator. The coefficients of internal consistency of all instruments for the current sample are presented in the Results section.

The shortened version of Conformity to Masculine Norms Inventory (CMNI 46) by Parent \& Moradi (2009) based on the revision of the longer one developed by Mahalik et al. (2003), measures traditional, hegemonic masculinity based on conformity to masculine role norms that are prevailing in the western culture. It comprises 9 subscales: Competition, Emotional Control, Risk-taking, Violence, Playboy, Self-reliance, Primacy of Work, Power over Women and Heterosexual Self-presentation. Participants respond to 46 items using a 4-point Likert scale ranging from $0=$ strongly disagree to $3=$ strongly agree. The evidence for convergent validity of the CMNI is provided by its significant correlations with other measures of masculinity (Mahalik, Talmadge, Locke, \& Scott, 2005).

The Emotional Self-Disclosure Scale (ESDS) developed by Snell, Miller \& Belk (2013) consists of 8 subscales, each containing five separate items. For this research, only three subscales were selected: Depression, Anxiety and Fear emotional-disclosure. They are selected on the basis of the intention to measure the tendency of disclosure of three emotions that are regarded as less "masculine" within the traditional definition of the male role. On a 6-point scale (from 0-never to 5-always), respondents report their preparedness to disclose these emotions with close persons. Lower score indicates lesser inclination to reveal emotions.

The Depression Anxiety Stress Scale (DASS) is a 42-item instrument designed to measure the three related negative emotional states of depression, anxiety and tension/stress (Lovibond \& Lovibond, 1995). Several studies provide support for the psychometric and conceptual basis of the DASS, particularly for non-clinical samples.

The self-esteem was assessed by the widely used Rosenberg's self-esteem scale (RSE) which demonstrates well established concurrent, predictive and construct validity (Rosenberg, 1979), whereas the life satisfaction component of subjective well-being was measured by using the popular Satisfaction With Life Scale (SWLS) developed and reviewed by Pavot \& Diener (1993).

The tendency towards taking or not taking health related risks was evaluated on the basis of three indicators. The risk regarding sexual health in terms of preventing (or not) unintended pregnancy, HIV infection and other sexually transmitted diseases was measured by one of the UCLA Multidimensional Condom Attitude Scales that has highest correlations with condom use (Helweg-Larsen, \& Collins, 1994). The degree of nicotine dependency was identified by the Cigarette Dependence Scale (CDS) by Etter et al., (2003), and 
for the alcohol use/addiction, we administered the AUDIT - Alcohol Use Disorder Identification Test developed by the World Health Organization in 1982. All participants also provided self-reported information on their education, marital status, sexual orientation and employment status.

\section{Procedure}

All included participants took part in this study voluntarily based on previously given informed consent and their participation did not involve any kind of compensation. Participants responded to the described self-report instruments that were administered by psychology students who have been trained and supervised by the author. The data gathering process took place in November 2019.

\section{RESULTS}

Table 1 shows the means, standard deviations, the coefficients of internal consistency (coupled with the number of items) and the Shapiro-Wilks test values for the included instruments, along with the CMNI-46 subscales. All instruments have satisfactory reliability coefficients, except for the subscale Power over women the internal homogeneity of which is somewhat below the critical value of $0.60 .^{3}$

Table 1. Descriptives for conformity to masculine norms, subjective well-being, selfesteem, emotional disclosure and different measurement of risk taking $(\mathrm{N}=310)$

\begin{tabular}{ccccccc}
\hline$M$ & $\begin{array}{c}X_{\min } \\
X_{\max }\end{array}$ & Range & $S D$ & $\alpha$-coef & $n$ & $\begin{array}{c}\text { Shapiro } \\
\text {-Wilks }\end{array}$ \\
\hline $\mathbf{6 4 . 2 2}$ & $\mathbf{0 - 1 3 8}$ & $\mathbf{1 6 - 1 0 6}$ & $\mathbf{1 3 . 5 6}$ & $\mathbf{0 . 6 5}$ & $\mathbf{4 6}$ & $\mathbf{0 . 9 9}$
\end{tabular}

CMNI 46- Conform
to Masculine Norms

$\begin{array}{lccccccc}\text { Competition } & 10.73 & 0-21 & 0-18 & 3.29 & 0.65 & 7 & 0.97^{* *} \\ \text { Emotional Control } & 9.18 & 0-18 & 0-18 & 3.54 & 0.75 & 6 & 0.94^{* *} \\ \text { Risk-taking } & 7.15 & 0-15 & 0-15 & 2.89 & 0.62 & 5 & 0.97^{* *} \\ \text { Violence } & 6.86 & 0-18 & 0-18 & 3.84 & 0.61 & 6 & 0.97^{* *} \\ \text { Playboy } & 4.56 & 0-12 & 0-12 & 3.09 & 0.78 & 4 & 0.94^{* *} \\ \text { Self-reliance } & 6.38 & 0-15 & 0-15 & 2.86 & 0.67 & 5 & 0.98^{* *} \\ \text { Primacy of Work } & 4.77 & 0-12 & 0-12 & 2.69 & 0.79 & 4 & 0.97^{* *} \\ \text { Power over Women } & 4.81 & 0-12 & 0-12 & 2.39 & 0.56 & 4 & 0.95^{* *} \\ \text { Heterosexual Self-presen- } & 9.86 & 0-18 & 0-18 & 5.03 & 0.77 & 6 & 0.97^{* *} \\ \text { tation } & & & & & & & \end{array}$

${ }^{3}$ Given the small number of items, which is probably the main source of lower homogeneity, this subscale is yet considered to be acceptably reliable and it was included in the analysis. 


\begin{tabular}{|c|c|c|c|c|c|c|c|}
\hline $\begin{array}{l}\text { DASS-Depression } \\
\text { Anxiety Stress Scale }\end{array}$ & 24.31 & $0-126$ & $0-94$ & 19.06 & 0.95 & 42 & $0.89^{* *}$ \\
\hline Depression & 6.69 & $0-37$ & $0-42$ & 7.39 & 0.92 & 14 & $0.95^{* *}$ \\
\hline Anxiety & 6.66 & $0-31$ & $0-42$ & 5.84 & 0.90 & 14 & $0.97^{* * *}$ \\
\hline Stress & 10.72 & $0-37$ & $0-42$ & 7.95 & 0.93 & 14 & $0.89^{* * *}$ \\
\hline $\begin{array}{l}\text { RSE-Rosenberg's self- } \\
\text { esteem scale }\end{array}$ & 55.23 & $10-70$ & $26-70$ & 9.16 & 0.76 & 10 & $0.96^{* *}$ \\
\hline $\begin{array}{l}\text { SWLS-Satisfaction } \\
\text { With Life Scale }\end{array}$ & 23.44 & $5-35$ & $5-35$ & 6.32 & 0.83 & 5 & $0.98^{* *}$ \\
\hline $\begin{array}{l}\text { ESDS-Emotional Self- } \\
\text { Disclosure Scale }\end{array}$ & 36.80 & $0-75$ & $0-59$ & 16.33 & 0.94 & 15 & 0.99 \\
\hline $\begin{array}{l}\text { Multidimensional } \\
\text { Condom Attitude Scale }\end{array}$ & 22.37 & $8-56$ & $10-56$ & 10.15 & 0.74 & 8 & $0.92^{* *}$ \\
\hline $\begin{array}{l}\text { AUDIT-Alcohol Use } \\
\text { Disorder Identification }\end{array}$ & 15.73 & $10-70$ & $10-32$ & 3.91 & 0.77 & 10 & $0.91^{* *}$ \\
\hline $\begin{array}{l}\text { CDS-Cigarette Depen- } \\
\text { dence Scale }\end{array}$ & 16.78 & $0-60$ & $0-59$ & 20.17 & 0.88 & 12 & $0.76^{* *}$ \\
\hline
\end{tabular}

Table 2 presents the correlations among study variables. As seen, self-esteem and life satisfaction are correlated only with few aspects of masculinity norms, but not with the general norm adherence. These two well-being facets are higher when the heterosexual self-presentation is higher and the self-reliance is lower. Satisfaction with life is also related to higher risk taking and primacy of work. Results suggest that for this age group of men, depression, anxiety and stress are related with the overall CMNI score, particularly due to the associations with self-reliance and maintaining the image of playboy and power over women. Expectedly, there is a significant correlation between the preparedness to share emotions with the conformity to masculine norms ( $r=-0.30)$, stemming mainly from the need for emotional control, but also with the self-reliance, risk taking and involvement in violence.

Negative attitude towards use of condoms seems to be related to widest variety of aspects of hegemonic masculinity norms. Actually, it is not associated only with emotional control, primacy of work and self-reliance, whereas the strongest links for the current age group are registered for the norms power over women and self-presentation as heterosexual.

Smoking and alcohol use are also correlated with the overall CMNI construct, but the only shared aspect of masculinity that supports these two habits is emotional control that does not participate in taking sexually related risk. The results presented in Table 2 suggest that the consumption of alcohol is more extensively interrelated with the different aspects of masculinity. Those norms 
that define manliness by the ability to take risks, responding violently and treating women as sexual objects are positively related to the alcohol use disorder.

Generally, results reveal that the norms least involved in determining the well-being and risk behaviours are competition (related only with condom use) and primacy of work (related only with life satisfaction).

Table 2. Correlations between conformity to masculine norms and its facets with subjective well-being, self-esteem, emotional disclosure and different measurement of risk taking

\begin{tabular}{|c|c|c|c|c|c|c|c|c|c|c|}
\hline & $\begin{array}{l}\text { Conf. } \\
\text { to } \\
\text { masc. } \\
\text { norms }\end{array}$ & $\begin{array}{l}\text { Compe- } \\
\text { tition }\end{array}$ & $\begin{array}{l}\text { Emo- } \\
\text { tion. } \\
\text { control }\end{array}$ & $\begin{array}{l}\text { Risk- } \\
\text { taking }\end{array}$ & $\begin{array}{l}\text { Vio- } \\
\text { lence }\end{array}$ & $\begin{array}{l}\text { Play- } \\
\text { boy }\end{array}$ & $\begin{array}{l}\text { Pri- } \\
\text { macy } \\
\text { of work }\end{array}$ & $\begin{array}{l}\text { Self- } \\
\text { reliance }\end{array}$ & $\begin{array}{l}\text { Power } \\
\text { over } \\
\text { women }\end{array}$ & $\begin{array}{l}\text { Heter. } \\
\text { self- } \\
\text { presen- } \\
\text { tation }\end{array}$ \\
\hline $\begin{array}{l}\text { Self- } \\
\text { esteem }\end{array}$ & 0.01 & 0.09 & -0.05 & 0.05 & -0.05 & -0.11 & 0.02 & $-0.18^{* *}$ & 0.03 & $0.13^{*}$ \\
\hline $\begin{array}{l}\text { Satisfact. } \\
\text { with life }\end{array}$ & 0.06 & 0.06 & -0.11 & $0.14^{*}$ & -0.04 & -0.07 & $0.14^{*}$ & $-0.21^{* *}$ & 0.10 & $0.14^{*}$ \\
\hline $\begin{array}{l}\text { Depres- } \\
\text { sion }\end{array}$ & $0.18^{* *}$ & 0.08 & 0.09 & -0.02 & 0.05 & $0.20^{* * *}$ & -0.03 & $0.18^{* *}$ & 0.07 & 0.02 \\
\hline Anxiety & $0.20^{* *}$ & 0.07 & $0.14^{*}$ & -0.02 & 0.03 & $0.13^{*}$ & 0.02 & $0.22^{* * *}$ & $0.15^{* *}$ & -0.02 \\
\hline Stress & $0.15^{* *}$ & 0.08 & 0.06 & -0.03 & 0.04 & $0.14^{*}$ & -0.02 & $0.20^{* *}$ & $0.18^{*}$ & 0.05 \\
\hline $\begin{array}{l}\text { Emo- } \\
\text { tional } \\
\text { disclosure }\end{array}$ & $-0.30^{* *}$ & -0.03 & $-0.43^{* *}$ & $-0.17^{* * *}$ & $-0.13^{*}$ & $-0.13^{*}$ & 0.02 & $-0.25^{* *}$ & -0.04 & -0.06 \\
\hline $\begin{array}{l}\text { Condom } \\
\text { avoid. att. }\end{array}$ & $0.33^{* *}$ & $0.12^{*}$ & 0.00 & $0.14^{*}$ & $0.16^{* *}$ & $0.23^{* *}$ & 0.04 & 0.07 & $0.34^{* *}$ & $0.25^{* *}$ \\
\hline $\begin{array}{l}\text { Alcohol } \\
\text { use }\end{array}$ & $0.24^{* *}$ & $0.12^{*}$ & $0.12^{*}$ & $0.14^{*}$ & $0.12^{*}$ & $0.34^{* *}$ & 0.02 & 0.06 & 0.02 & -0.01 \\
\hline $\begin{array}{l}\text { Cigarette } \\
\text { use }\end{array}$ & $0.13^{*}$ & 0.05 & $0.14^{*}$ & $0.17^{*}$ & 0.03 & 0.02 & 0.04 & $0.17^{* *}$ & 0.06 & 0.01 \\
\hline
\end{tabular}

\section{Discussion}

The findings from this study suggest that from the perspective of psychological well-being, the adherence to masculine norms might have both positive and negative outcomes. The detailed picture once again re-affirms the need for avoiding the use of only total CMNI-46 score in examining the effects of male role adherence to men's health, because it obscures the more complex relationships between conformity to specific norms and men's well-being (Gerdes \& Levant, 2018). This is an especially important note if taken into account 
that these norms have different meanings and degree of social acceptability in different cultural contexts.

Thus, contrary to the hypothesis, neither self-esteem nor life satisfaction are related to the overall CMNI-46 score. However, primacy of work and heterosexual self-presentation are positively connected with the well-being. On the other hand, self-reliance is negatively associated with both self-esteem, satisfaction with life and ability to disclose emotions and positively associates with depression, anxiety and stress and tobacco use. This means that for this particular age group and culture, the gender expectation to deal on their own with all problems carries the highest risks to general well-being. This 'cluster' of correlations is in line with some previous studies that have shown poorer mental well-being among men who are highly self-reliant (Milner, et al., 2018, Milner, Shields \& King, 2019; Rice, Fallon \& Bambling, 2011).

Apart from self-reliance, another subscale with clear negative consequences to men's well-being is playboy, which predominantly denotes wishing to have multiple sexual partners. As acknowledged in many other studies (Burn \& Ward, 2005; Iwamoto, 2014), it is related to alcohol abuse, condom avoidance and to depression, stress and anxiety.

In accordance with several other studies, adherence to risk taking as a norm generates largely mixed findings. In this study, risk taking is related with alcohol and tobacco use and with avoiding condom use, as well as with being less open to showing emotions, however, respondents with higher risk taking endorsement are more satisfied with life. Similarly, in a couple of other studies, risk-taking was associated with courage, endurance and at the same time, with sexually aggressive behaviour and substance abuse (Gerdes \& Levant, 2018). Defining masculinity through the inclination to take risks, in the context of the current pandemic, can be treated as an additional serious potential threat to men's health and the health of their close ones.

This research, in addition to clearly confirming the need to analyse various aspects of masculinity on men's behaviour, suggests that for this age group, hegemonic masculinity brings more potential and actual harm than benefit. In that respect, as Kaufman (1994) observed, men pay the cost, sometimes not at all trivial, for the way they have learned to embody and exercise power. On the other hand, the findings point out to the possibility of distinguishing between the effects of different aspects of traditional masculinity, which provides opportunity for redefining those that generate negative consequences and at the same time, challenges the societal responsibility of policy makers, especially in the field of education.

\section{Limitations}

Two most important limitations of this research are that it is an exploratory study, without a theoretical model to test and that the sample, in spite being large enough and relatively heterogeneous from perspective of sociodemographic characteristics, is convenient and thus potentially biased. 


\section{References:}

Bleidorn, W., Arslan, R. C., Denissen, J. J. A., Rentfrow, P. J., Gebauer, J. E., PotTER, J., \& Gosling, S. D. (2016). Age and gender differences in self-esteem-A cross-cultural window. Journal of Personality and Social Psychology, 111(3), pp. 396-410. doi.org/10.1037/pspp0000078.

BotTORFF, J. L., Haines-SAAH, R., Kelly, M. T., OlifFe, J. L., TORChalla, I., POOLE, N., ...PHILLIPS, J. C. (2014). Gender,smoking and tobacco reduction and cessation: A scoping review. International Journal for Equity in Health, 13(1), pp. 1-15. doi.org/10.1186/s12939-014-0114-2.

BURN, S. M., \& WARD, A. Z. (2005). Men's conformity to traditional masculinity and relationship satisfaction. Psychology of Men $\mathcal{E}$ Masculinity, 6(4), pp. 254-263.

BURNS, S.M. \& MAHALIK, .JR. (2006). Physical health, self-reliance, and emotional control as moderators of the relationship between locus of control and mental health among men treated for prostate cancer. Journal of Behavioral Medicine, 29, pp. 561-572.

CONNELL, R. W. (2005). Masculinities (2nd ed.). Berkeley: University of California Press.

DiDonato, M. D., \& Berenbaum, S. A. (2013). Predictors and consequences of gender typicality: The mediating role of communality. Archives of Sexual Behavior, 42, pp. 429-436. doi.org/10.1007/s0508-012-9955-1.

Gerdes, Z. T., LEVANT, R. F. (2018). Complex relationships among masculine norms and health/well-being outcomes: Correlation patterns of the conformity to masculine norms inventory subscales. American Journal of Men's Health, 12(2), pp. 229-240.

Corby, B. C., Hodges, E. V., \& Perry, D. G. (2007). Gender identity and adjustment in Black, Hispanic, and White pre-adolescents. Developmental Psychology, 43, pp. 261-266.

EtTer, J.F., LeHoueZec, J., \& Perneger, T.V. (2003). A self-administered questionnaire to measure addiction to cigarettes: The Cigarette Dependence Scale. Neuropsychopharmacology. 28(2), pp. 359-70.

Helweg-LARsen, M., \& COllins, B. E. (1994). The UCLA Multidimensional Condom Attitudes Scale: Documenting the complex determinants of condom use in college students. Health Psychology, 13, pp. 224-237.

HeILMAN, M. E., \& WALLEN, A. S. (2010). Wimpy and undeserving of respect: Penalties for men's gender-inconsistent success. Journal of Experimental Social Psychology, 46, pp. 664-667. doi:10.1016/j.jesp.2010.01.008

Hussman, J. (2015). 'Drink like a man': How gender roles impact alcohol use among emerging adults in Canada. Political Science, Corpus ID: 85524059, 
Retrieved from https://www.semanticscholar.org/paper/\%60Drink-Likea-Man\%27\%3A-How-Gender-Roles-Impact-Alcohol-

Hussman/93147a00d5ff3db1039e7b5bab6ee62dd43233d7

IWAMOTO, D.K., LIAO, L. \& LiU, W.M. (2010). Masculine norms, avoidant coping and depressive symptoms among Asian American men. Psychology of Men and Masculinity,11, pp. 15-24.

Iwamoto, D.K. Gordon, D., Oliveros, A., Perez Cabello, A., Brabham, T, LANZA, S \& DYSON, W. (2013). The Role of Masculine Norms and Informal Support on Mental Health in Incarcerated Men. Psychology of Men and Masculinity, 13(3), pp. 283-293.

Iwamoto, D. K., Corbin, W., Lejuez, C., AND MacPherson, L. (2014). College men and alcohol use: Positive alcohol expectancies as a mediator between distinct masculine norms and alcohol use. Psychology of Men and Masculinity, 15(1), pp. 29-39.

JeWELL, J. A., \& BROWN, C. S. (2014). Relations among gender typicality, peer rela-tions, and mental health during early adolescence. Social Development, 23, pp. 137-156. doi:10.1111/sode.12042

KAUFMAN, M. (1994). Men, feminism, and men's contradictory experiences of power. In H. Brod and M. Kaufman (Eds.), Research on men and Masculinities Series: Theorizing masculinities (pp. 142-164). Thousand Oaks, CA: SAGE Publications, Inc.

KiselicA, M. S., BENTON-Wright, S., \& ENGlar-CARLSON, M. (2016). Accentuating positive masculinity: A new foundation for the psychology of boys, men, and masculinity. In Y. J. Wong \& S. R. Wester (Eds.), APA handbook of men and masculinities (pp. 51-79). Washington, DC: American Psychological Association.

KIVEL, P. (1998). Men's work: How to stop the violence that tears our lives apart. Center City, MN: Hazelden Publishing.

LoviBOnd, S.H. \& LoviBOND, P.F. (1995). Manual for the Depression Anxiety \& Stress Scales. (2 Ed.) Sydney: Psychology Foundation.

MATUD, M. P., BETHENCOURT, J. M., \& IBÁÑEZ, I. (2014) Relevance of gender roles in life satisfaction in adult people, Personality and Individual Differences, 70, pp. 206-211.

MAHALIK, J.R., LOCKE, B.D., LuDlOW, L.H., DiEMER, M.A., SCOTT, R.P.J., GOTTFRIED, M., \& FREITAS, G. (2003). Development of the Conformity to Masculine Norms Inventory. Psychology of Men and Masculinity, 4, pp. 325. doi:10.1037//1524-9220.4.1.3

MAHALIK, J.R., TALMADGE, W.T., LOCKE, B.D., \& SCOTT, R.P.J. (2005). Using the Conformity to Masculine Norms Inventory to work with men in a clinical setting. Journal of Clinical Psychology, 61, pp. 661-674. doi:10.1002/jclp. 20101. 
Milner A., KaVAnagh A., King T., CURRIER D. (2018). The influence of masculine norms and occupational factors on mental health: Evidence from the baseline of the Australian longitudinal study on male health. American Journal of Men's Health, 12(4), pp. 696-705.

MiLnER, A., SHIELDS, M. \& KING, T. (2019). The Influence of Masculine Norms and Mental Health on Health Literacy among Men: Evidence From the Ten to Men Study. American Journal of Men's Health 13(5), doi: 10.1177/ 1557988319873532.

MORROW, M., AND BARRACLOUGH, S. (2010). Gender equity and tobacco control: Bringing masculinity into focus. Global Health Promotion, 17/1, pp. 21-8.

NG, N., WeINEHALL, L., AND ÖHMAN, A. (2007). 'If I don't smoke, I'm not a real man' - Indonesian teenage boys' views about smoking. Health Education Research, 22(6), pp. 794-804.

NOAR, S.M., AND MOROKOFF, P.J. (2002). The relationship between masculinity ideology, condom attitudes, and condom use stage of change: A structural equation modeling approach. International Journal of Men's Health, 1(1), pp. 43-58.

PARENT, M. C., \& MORADI, B. (2009). Confirmatory factor analysis of the Conformity to Masculine Norms Inventory and development of the Conformity to Masculine Norms Inventory-46. Psychology of Men \& Masculinity, 10, pp. 175-189. doi:10.1037/a0015481.

Pavot, W., \& Diener, E. (1993). Review of the Satisfaction with Life Scale. Psychological Assessment, 5, pp. 164-172.

RAgOnese, C., Shand, T., \& BARKer, G. (2019). Masculine Norms and Men's Health: Making the Connections. Washington, DC: Promundo-US.

Reidy, D. E., BROOKMEYer, K. A., Gentile, B., Berke, D. S., AND Zeichner, A. (2016). Gender Role Discrepancy Stress, High-Risk Sexual Behavior, and Sexually Transmitted Disease. Archives of Sexual Behavior, 45(2), pp. 459465.

Rice S., FAllon B., BAMBling M. (2011). Men and depression: The impact of masculine role norms throughout the lifespan. The Australian Educational and Developmental Psychologist, 28(2), pp. 133-144.

RosenberG, M. (1979). Conceiving the Self. New York: Basic Books.

Ruble, D. N., MARtin, C. L., \& Berenbaum, S. A. (2006). Gender development. In W. Damon \& R. M. Lerner (Series Eds.) \& N. Eisenberg (Vol. Ed.), Handbook of child psychology: Vol 3. Social, emotional, and personality development (pp. 858-932). Hoboken, NJ: Wiley.

Silva, T.S., Christino, J.M.M., Moura, L.R.C., Morais, V.H.F. (2019). Gender and Alcohol Consumption among Young people: Evaluation and Validation of Conformity to Masculine Norms Inventory. Cien Saude Colet., 24(9), pp. 3495-3506. 
SkinNer, O.D., KuRTZ-CosteS, B, WoOD, D. \& ROWLEY, S.J. (2018). Gender Typicality, Felt Pressure for Gender Conformity, Racial Centrality, and SelfEsteem in African American Adolescents, Journal of Black Psychology, Vol. 44(3), pp. $195-218$.

SNELL, W. E., JR., MiLLER, R. S., \& BeLK, S. S.. (2013).The Emotional Self- Disclosure Scale (ESDS). Measurement Instrument Database for the Social Science. Retrieved November $10^{\text {th }} 2019$ from www.midss.ie

UY, P. J., MAsSOTH, N. A., AND GotTdiener, W. H. (2014). Rethinking male drinking: Traditional masculine ideologies, gender-role conflict, and drinking motives. Psychology of Men and Masculinity, 15(2), pp. 121-128. 